\title{
Dynamic changes in genetic diversity, drug resistance mutations, and treatment outcomes of falciparum malaria from the low-transmission to the pre-elimination phase on the islands of São Tomé and Príncipe
}

Ying-An Chen', Tsen-Ju Shiu², Lien-Fen Tseng ${ }^{3}$, Chien-Fu Cheng ${ }^{3}$, Wei-Liang Shih ${ }^{2,4,6}$,

Arlindo Vicente de Assunção Carvalho ${ }^{5}$ and Kun-Hsien Tsai ${ }^{1,3,4,6^{*}}$ (D)

\begin{abstract}
Background: With effective vector control and case management, substantial progress has been made towards eliminating malaria on the islands of São Tomé and Príncipe (STP). This study assessed the dynamic changes in the genetic diversity of Plasmodium falciparum, the anti-malarial drug resistance mutations, and malaria treatment outcomes between 2010 and 2016 to provide insights for the prevention of malaria rebounding.

Methods: Polymorphic regions of merozoite surface proteins 1 and 2 ( $m s p 1$ and $m s p 2$ ) were sequenced in 118 dried blood spots (DBSs) collected from malaria patients who had visited the Central Hospital in 2010-2016. Mutations in the multi-drug resistance I (pfmdr1), chloroquine resistance transporter (pfcrt), and kelch 13 (pfk13) genes were analysed by polymerase chain reaction-restriction fragment length polymorphism (PCR-RFLP) and sequencing in 111 DBSs. A total of 7482 cases that completed a 28-day follow-up were evaluated for treatment outcomes based on the microscopic results. Regression models were used to characterize factors associated with levels of parasite density and treatment failures.

Results: Parasite strains in STP showed significant changes during and after the peak incidence in 2012. The prevalent allelic type in msp1 changed from $\mathrm{K} 1$ to MAD20, and that in msp2 changed from 3D7/IC to FC27. The dominant alleles of drug-resistance markers were pfmdr1 86Y, 184F, D1246, and pfcrt 76 T (Y-F-D-T, 51.4\%). The average parasite density in malaria cases declined threefold from low-transmission (2010-2013) to pre-elimination period (2014-2016). Logistic regression models showed that patients with younger age (OR for age $=0.97-0.98, p<0.001)$, higher initial parasite density ( $\log _{10}$-transformed, $\mathrm{OR}=1.44, \mathrm{p}<0.001$ ), and receiving quinine treatment (compared to artemisininbased combination therapy, $\mathrm{OR}=1.91-1.96, \mathrm{p}<0.001$ ) were more likely to experience treatment failures during follow-up.
\end{abstract}

Conclusions: Plasmodium falciparum in STP had experienced changes in prevalent strains, and increased mutation frequencies in drug-resistance genes from the low-transmission to the pre-elimination settings. Notably, patients

\footnotetext{
*Correspondence: kunhtsai@ntu.edu.tw

${ }^{1}$ Institute of Environmental and Occupational Health Sciences, College of Public Health, National Taiwan University, Taipei, Taiwan

Full list of author information is available at the end of the article
}

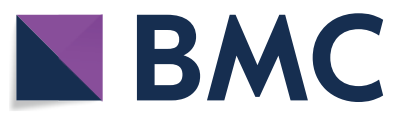

(c) The Author(s) 2021. Open Access This article is licensed under a Creative Commons Attribution 4.0 International License, which permits use, sharing, adaptation, distribution and reproduction in any medium or format, as long as you give appropriate credit to the original author(s) and the source, provide a link to the Creative Commons licence, and indicate if changes were made. The images or other third party material in this article are included in the article's Creative Commons licence, unless indicated otherwise in a credit line to the material. If material is not included in the article's Creative Commons licence and your intended use is not permitted by statutory regulation or exceeds the permitted use, you will need to obtain permission directly from the copyright holder. To view a copy of this licence, visit http://creativecommons.org/licenses/by/4.0/. The Creative Commons Public Domain Dedication waiver (http://creativeco mmons.org/publicdomain/zero/1.0/) applies to the data made available in this article, unless otherwise stated in a credit line to the data. 
with younger age and receiving quinine treatment were more likely to show parasitological treatment failure during follow-up. Therapeutic efficacy should be carefully monitored to inform future treatment policy in STP.

Keywords: São Tomé and Príncipe, Malaria, Plasmodium falciparum, Merozoite surface proteins, Antimalarial drug resistance mutations, Recurrence

\section{Background}

Although global malaria mortality fell by $60 \%$ over 2000 to 2019, the progress has leveled off in recent years, with sub-Saharan Africa bearing the highest burden of the disease [1]. High-transmission countries aim at getting back on track to reduce mortality and morbidity, while low-transmission countries aim at eliminating malaria by sustaining the control effort and preventing a rebound in transmission [2, 3]. São Tomé and Príncipe (STP), an island nation located in Central West Africa, has made significant progress toward a low-transmission country through effective vector control interventions $[4,5]$. Malaria elimination in STP is promising with the benefits of the relatively isolated location, small population, and single vector and parasite species responsible for malaria transmission $[4,6]$. However, STP's progress towards malaria elimination is being threatened by a potential rebound in malaria cases, emergence of insecticide resistant vectors and increased human mobility [4, 7]. In response to this situation, the Taiwan Anti-Malaria Advisory Mission has partnered with the government of STP to reinforce case follow-up by establishing a realtime electronic case management system, and preserving residual dried blood spots (DBSs) from malaria patients for implementation research. By integrating case surveillance data and parasite's genetic information, the dynamic changes of parasites over the control period can be tracked, mainly focusing on the genetic diversity, antimalarial drug resistance, and treatment effectiveness in Plasmodium falciparum.

The genetic structure of $P$. falciparum in STP was studied before 2004 by analysing the diversity levels of microsatellite loci [8]. The authors detected differences in parasite populations across 1997, 2000, and 2004, showing that local malaria control strategies could cause dynamic changes in parasite populations [8]. Over a decade later, with the expansion and transformation of the national malaria control program, changes in the parasite populations were expected but have not yet been proven. Therefore, this study tracked the genetic diversity of parasites using the merozoite surface protein 1 and 2 ( $m s p 1$ and $m s p 2$ ). MSP1 and MSP2 are antigens targeted by host-immune responses during blood-stage invasion $[9,10]$, and are polymorphic markers for identifying genetically distinct parasite subpopulations [11, 12]. MSP1 can be divided into three allelic types, K1, MAD20, and RO33, based on the variable sequences in the block 2 region [13]. MSP2 can be grouped into two dimorphic families, FC27 and 3D7/IC, with different repetitive patterns in the block 3 region [14]. The genetic structure of parasite populations over time can be traced by genotyping these markers in this longitudinal study.

Malaria is diagnosed through passive case detection by microscopy in hospitals and district health centers and through mass screening by rapid diagnostic tests (RDTs, immunochromatographic malaria combo cassette test) [7]. A 3-day course of artesunate-amodiaquine (ASAQ, first-line drug) was given to uncomplicated outpatients, and intravenous quinine was given to severe malaria cases and pregnant women during their first trimester, according to local regulations until 2018 [7, 15]. To follow-up the treatment outcomes, local healthcare workers would visit patients on days $3,7,14,21$, and 28 after treatment to collect blood specimens, making blood smears for microscopic examination, and dried blood spots (DBSs) for other research analysis. The second-line drug, artemether-lumefantrine (AL, Coartem ${ }^{\circledR}$, Novartis), was given to patients with remaining parasites at the followup day after the initial treatment $[7,16]$. Primaquine was given to patients showing gametocytes during follow-up. A small proportion of recurrent infections observed in STP raised the concerns of possible drug resistance in the parasites. Artemisinin resistance is known to be associated with mutations in the propeller domain of kelch 13 (pfk13) [17]. Resistance to ACT partner drugs, including amodiaquine (AQ) and lumefantrine (LF) used in STP, is associated with gene mutations in the multi-drug resistance I ( $p f m d r 1)$ and chloroquine resistance transporter $(p f c r t)[18,19]$. Thus, this study genotyped these markers coupled with case follow-up data to screen the drug-resistance markers and investigate risk factors for treatment failures in STP.

\section{Methods \\ Ethics statement}

The transfer, shipment, and utilization of DBSs and encrypted case surveillance data for research analysis in Taiwan were approved by both the Centro Nacional de Endemias (CNE) in STP $\left(\mathrm{OF}^{\circ} \mathrm{N}^{\circ} 20 / \mathrm{P}^{\circ} \mathrm{CNE} / 2016\right)$ and the Research Ethics Committee of National Taiwan University Hospital in Taiwan (NTUHREC No. 201110023RD). 


\section{Study site}

STP is located in the Gulf of Guinea, approximately $300 \mathrm{~km}$ off the coast of Gabon [20]. The total area is $1001 \mathrm{~km}^{2}$ with nearly 200,000 residents [4]. São Tomé main island consists of six administrative districts, Água Grande, Mé-Zóchi, Lobata, Cantagalo, Lembá, and Caué (Fig. 1). Príncipe offshore island is $173 \mathrm{~km}$ away from the São Tomé island. The population is primarily concentrated in the plains along the east coast of São Tomé island [4]. Rainfall is frequent throughout the year, except for the dry season from June to early September [4].

\section{Genomic DNA extraction from dried blood spots (DBSs)}

The DBSs were collected from patients who had visited the Central Hospital Ayres de Menezes (HAM) located in the capital district, Água Grande, from 2010 to 2016.
This study analyzed two sample sets. First, $m s p 1$ and msp 2 were sequenced in 118 DBSs (day-0, pre-treatment) to identify the infecting parasite strains. In the second sample set, 92 matched samples were from 41 recurrent infections, which contained 41 pre-treatment (day- 0$)$ and 51 post-treatment samples (day- $R, R=3,7,14,21,28$, the follow-up days tested positive after treatment). Among the 41 recurrent infections, 36 had one day- $R$ sample, and 5 had more than one day- $R$ samples because they showed parasitaemia on multiple follow-up days. Additionally, 19 pre-treatment samples with negative infections in post-treatment samples were also genotyped for drug-resistance markers. Therefore, the total number of DBSs for drug-resistance genotyping was 111, including 60 pre-treatment (day- 0 ) and 51 post-treatment (day- $R$ ) samples.

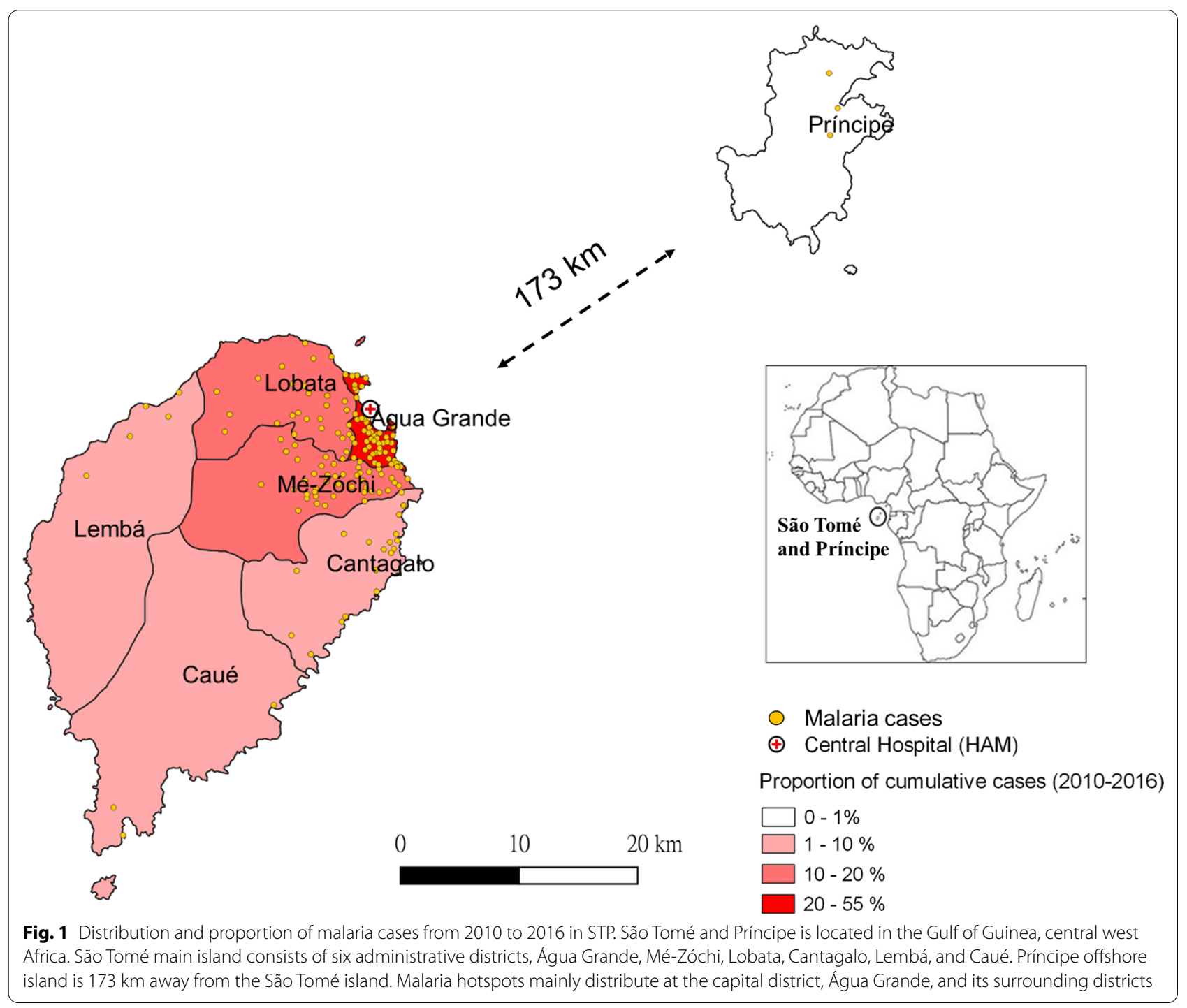


Genomic DNA was extracted from three 6-mm circular punches on DBSs using the Geneaid Genomic DNA Mini Kit for Tissue (Geneaid Biotech Ltd., Taipei, Taiwan). The blood spots were immersed in $1 \mathrm{~mL}$ of lysis buffer and protease $\mathrm{K}$ mixture followed by shaking and incubation at $60{ }^{\circ} \mathrm{C}$ for $1.5 \mathrm{~h}$. The liquid mixture was then transferred to a DNA-binding membrane and washed according to the manufacturer's instructions. Genomic DNA was eluted in $80 \mu \mathrm{L}$ of elution buffer and stored at $-20{ }^{\circ} \mathrm{C}$ for further analysis.

\section{PCR and sequencing of $m s p 1$ and $m s p 2$}

Block 2 of $m s p 1$ and block 3 of $m s p 2$ sequences were amplified using primer pairs designed in Wooden et al. [21]. The PCR reactions for $m s p 1$ and $m s p 2$ contained $10 \mu \mathrm{L}$ of $2 \mathrm{X}$ HotStarTaq Master Mix (Qiagen, Hilden, Germany), $10 \mu \mathrm{M}$ of forward and reverse primers, $3 \mu \mathrm{L}$ of DNA template, and RNase-free water to a total volume of $20 \mu \mathrm{L}$. The PCR condition started with an initial denaturation at $95^{\circ} \mathrm{C}$ for $15 \mathrm{~min}$, followed by 40 cycles of denaturation at $95^{\circ} \mathrm{C}$ for $30 \mathrm{~s}$, annealing at $50{ }^{\circ} \mathrm{C}$ for $30 \mathrm{~s}$, extension at $72{ }^{\circ} \mathrm{C}$ for $30 \mathrm{~s}$, and a final extension at $72{ }^{\circ} \mathrm{C}$ for $10 \mathrm{~min}$ using the Biometra TRIO Thermal Cycler (Analytik Jena AG, Jena, Germany). The fragment lengths of the amplified products varied from 200 to $400 \mathrm{bp}$ in $m s p 1$, and 400 to $600 \mathrm{bp}$ in $m s p 2$. The confirmed PCR products were gel-purified using QIAquick ${ }^{\circledR}$ Gel Extraction Kit (Qiagen, Hilden, Germany) and sequenced by Applied Biosystems 3730xl DNA Analyzer (Thermo Fisher Scientific, Waltham, MA, USA). The multiplicity of infection (MOI) of $m s p 1$ and $m s p 2$ genes was calculated by averaging the number of amplified bands (haplotypes) per sample.

In addition, nested PCR (nPCR) of $m s p 1$ and $m s p 2$ were performed to discriminate new infections (due to new infectious mosquito bites) and recrudescence (incomplete clearance of asexual parasites after treatment) in matched recurrent samples $(\mathrm{n}=92)$ using the standard methods designed by WorldWide Antimalarial Resistance Network (WWARN) [22, 23]. The nPCR products were confirmed by capillary electrophoresis using the QIAxcel Advanced System (Qiagen, Hilden, Germany) and gel-purified for sequencing. Recrudescence was determined by at least one allele at each locus that was identical between the matched pre and posttreatment samples. New infection was defined when all alleles identified from the post-treatment samples were different from the pre-treatment samples [24].

\section{Genotyping of polymorphisms on pfmdr1, pfcrt, and pfk 13} The pfmdr1 N86Y, Y184F, D1246Y, pfcrt K76T, and pfk13 gene polymorphisms were analyzed in a total of 60 pre-treatment and 51 post-treatment samples. PCR sequencing was performed to detect pfmdr1 N86Y, Y184F, and $p f k 13$ gene polymorphisms [25, 26]. PCR reactions consisted of $10 \mu \mathrm{L}$ of $2 \mathrm{X}$ HotStarTaq Master Mix, $10 \mu \mathrm{M}$ of forward and reverse primers, $3 \mu \mathrm{L}$ of DNA template, and RNase-free water to a total volume of $20 \mu \mathrm{L}$. The PCR program started with an initial denaturation at $95{ }^{\circ} \mathrm{C}$ for 15 min followed by 40 cycles of denaturation at $95{ }^{\circ} \mathrm{C}$ for $30 \mathrm{~s}$, annealing at $50{ }^{\circ} \mathrm{C}$ for pfmdr 1 and $54{ }^{\circ} \mathrm{C}$ for $p f k 13$, extension at $72{ }^{\circ} \mathrm{C}$ for $30 \mathrm{~s}$, and a final extension at $72{ }^{\circ} \mathrm{C}$ for $10 \mathrm{~min}$. The amplicon sizes were $353 \mathrm{bp}$ and $986 \mathrm{bp}$ for the $p f m d r 1$ and $p f k 13$ genes, respectively. PCR products were sequenced after confirming sizes by gel electrophoresis.

The $p f m d r 1 \mathrm{D} 1246 \mathrm{Y}$ and $p f c r t \mathrm{~K} 76 \mathrm{~T}$ alleles were identified by PCR-RFLP. PCR products of $p f m d r 1$ were digested by EcoRV (20,000 units/mL, New England Biolabs, Massachusetts, USA), and pfcrt fragments were digested by ApoI endonuclease $(10,000$ units/mL, New England Biolabs, Massachusetts, USA) [27, 28]. After the digestion, DNA patterns were visualized on $2.5 \%$ agarose gel to determine the polymorphic types. In addition, a subset of the pfcrt products was further sequenced to identify the pfcrt 72-76 haplotype. Genomic DNA of the 3D7 clone (Catalog Number PRA-405D, ATCC, Virginia, USA) was the wild-type control for the genotyping results of $p f m d r 1, p f c r t$, and $p f k 13$ genes.

\section{Sequence alignment and data analysis}

DNA sequences of $m s p 1$ and $m s p 2$ were quality-checked, translated into protein sequences, and aligned based on their structures [29] using Lasergene SeqMan version 7.1 and BioEdit version 7.0. The maximum likelihood (ML) tree was constructed by bootstrapping 100 times using the general time reversible (GTR) model in the MEGA version 7.0. Comparisons of drug-resistance alleles between matched pre-treatment (day- 0 ) and post-treatment (day-R) samples were examined by McNemar's test. Mixed alleles were treated as mutants in McNemar's test.

\section{Characterization of parasite density levels and treatment outcomes of malaria cases in STP}

From 2010 to 2016, 10,019 cases were reported by the Central Hospital Ayres de Menezes (HAM). However, only 7482 subjects with complete records were enrolled in the analysis (excluding 2537 cases with incomplete baseline information and those lost to follow-up). The case surveillance data documented patient's record number, gender, age, residency (district and village), date of confirmed diagnosis, microscopic results before the initial treatment (day-0), treatment regime, and microscopic results at follow-up (days $3,7,14,21$, and 28 posttreatment). The parasite density (parasite counts per $\mu \mathrm{L}$ blood) from microscopic results was $\log _{10}$-transformed. 
The linear regression model was used to characterize the significant factors associated with the levels of parasite density.

All patients enrolled in the analysis were classified into one of the following groups: adequate clinical and parasitological response (ACPR), early treatment failure (ETF), insufficient clearance on day 3 (ISC), late parasitological failure (LPF), and gametocyte carriage
(GC), as shown in Fig. 2. This classification scheme was modified from the WHO guideline [24, 30]. ISC and GC were the two groups not specified in the WHO guideline, while other groups followed the WHO's definition [30]. Since recurrent malaria was attributed to the recurrence of asexual parasitaemia [31]; patients showing only sexual parasitaemia (gametocytes) after treatment were separately classified as the gametocyte

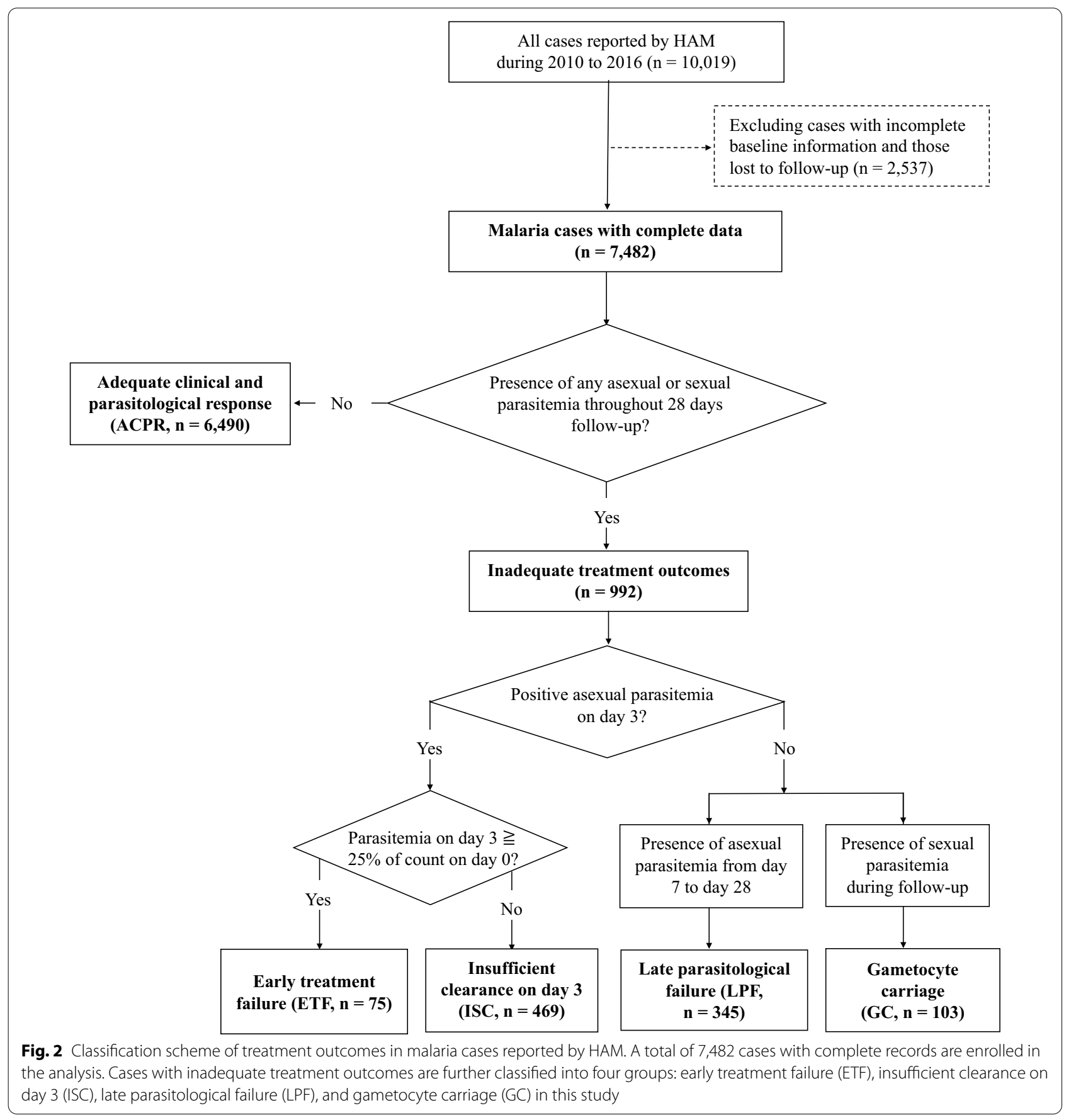


carriage (GC) group in this study. Early treatment failure (ETF) was defined as the presence of danger signs or higher parasitaemia on day 3 , i.e., $\geq 25 \%$ of the parasite counts on day-0 [24]. Therefore, those who showed mild symptoms and decreased parasite counts on day 3 were classified into the insufficient clearance (ISC) group in this study.

Finally, multivariate logistic regression models evaluated factors associated with early (day 3 positive) and late (day 7-28 positive) parasitological failures after treatment. The host-related variables were the patient's age, gender (female as reference), and residency (urban districts included Água Grande, Mé-Zóchi, and Lobata compared to other districts). Time-related variables considered the periods and seasons of the initial infections (the year was transformed to "period" as defined in Fig. 3, and the month was transformed to "endemic season" as defined in Additional file 1: Fig. S1). Treatment outcomes of ACT (reference) and quinine groups were compared in the logistic regression models. Mediation analysis was performed to clarify the relationship between the initial parasite density, treatment types, and parasitological failures. All statistical analyses were performed by $\mathrm{R}$ version 4.0.2.

\section{Results}

Sequence diversity of $m s p 1$ block 2 in P. falciparum isolates from STP

Twenty-two haplotypes were identified in msp1 block 2 from 118 samples collected between 2010 and 2016 (GenBank accession numbers MW001371-MW001392). Nine haplotypes belonged to the K1 family (KH1-KH9), nine belonged to the MAD20 family (MH1-MH8, haplotype $\mathrm{MH} 3$ was translated from two nucleotide sequences, MH3-1 and MH3-2), and four belonged to the RO33 family (RH1-RH4). The majority of cases $(93.2 \%, 110 / 118)$ were infected by a single clone of $m s p 1$, with only $6.8 \%$ $(8 / 118)$ of cases showing multi-clones of $m s p 1$ haplotypes (mean MOI $=1.08$ ). K1, MAD20, and RO33 haplotypes were identified in $34.7 \%$ (41/118), $44.1 \%(52 / 118)$, and $21.2 \%(25 / 118)$ of the total isolates, respectively.

The K1 and MAD20 alleles shaped the diversity by rearranging a number of tri-peptide repeat units (the R1 region of Additional file 1: Fig. S2). According to

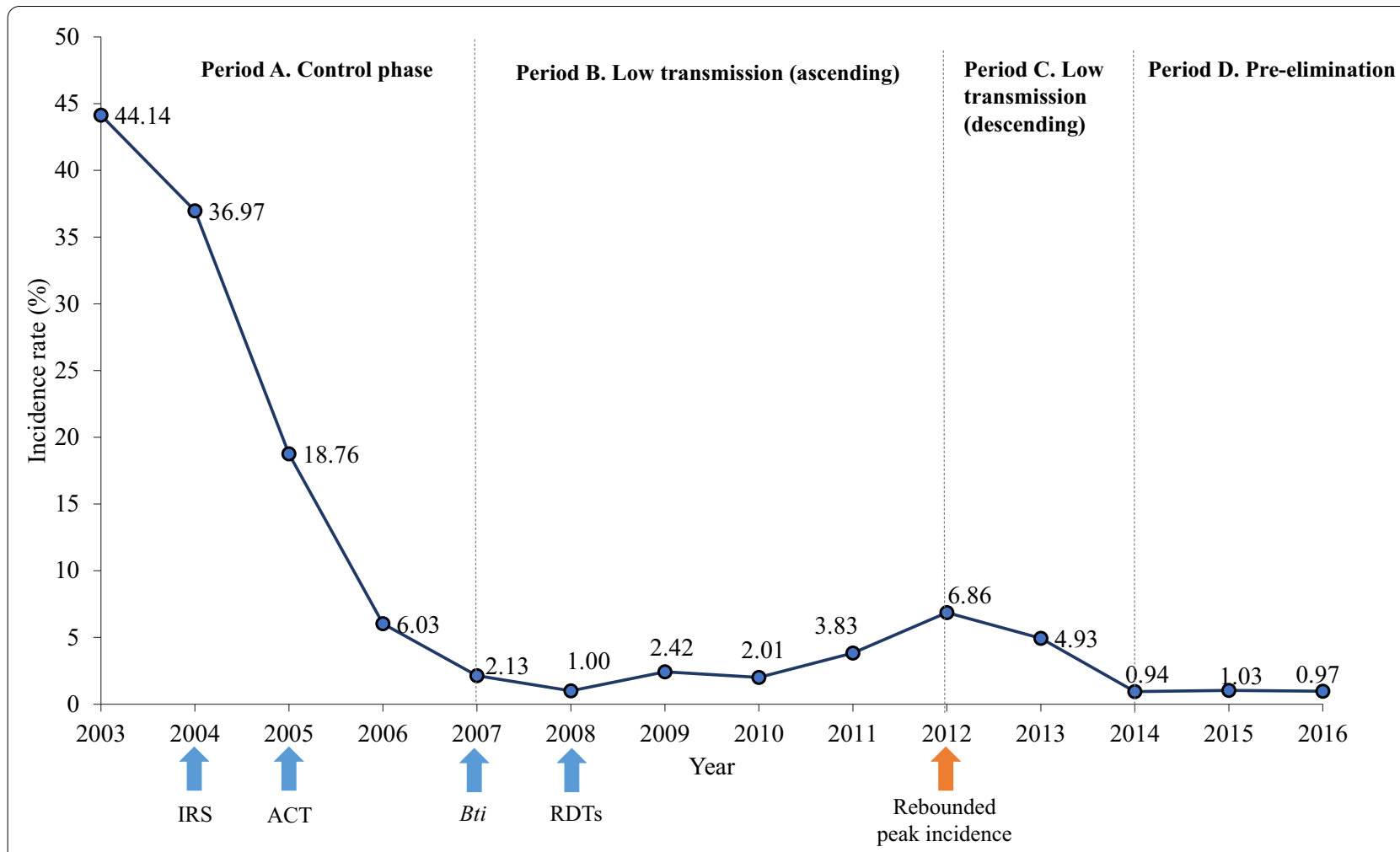

Fig. 3 Classification of periods based on the annual malaria incidence rate in STP. Malaria incidence had dropped by $40 \%$ during the control phase from 2000 to 2007 due to the prompt deployment of indoor residual spraying (IRS), and the introduction of artemisinin-based combination therapy (ACT). Between 2007 and 2012, the incidence rate was controlled under 5\% by applying Bacillus thuringiensis israelensis (Bti) for larval control, and rapid diagnostic tests (RDTs) for mass screening. Subsequently, there was a slight increase in the incidence, and the rebounded peak was shown in 2012. After the peak incidence, malaria incidence was again controlled to $\sim 1 \%$ and reaching the pre-elimination phase 
the repetitive patterns and arrangement, two subgroups were further divided in the $\mathrm{K} 1$ and MAD20 families on the phylogenetic tree (Additional file 1: Fig. S3). One group contained haplotypes that were more widespread relative to the other group. On the other hand, the RO33 haplotypes were unique sequences without any repeats and presented the least polymorphisms in the amplified region.

Allele distribution of $m s p 1$ had changed during, and after the peak incidence in $2012\left(x^{2}=7.94, \mathrm{df}=2\right.$, $\mathrm{p}=0.02)$ that prevalence of $\mathrm{K} 1$ alleles decreased from 54 to $35 \%$; prevalence of MAD20 ranged from 42 to $49 \%$, and that of RO33 alleles increased from 4 to $23 \%$ (Fig. 4). The increase of MAD20 and RO33 alleles was mainly due to the increased prevalence of haplotypes MH3 and RH1, for more than 20\% growth after 2012, and replaced $\mathrm{K} 1$ haplotypes becoming the predominant types after the peak incidence.

\section{Sequence diversity of $m s p 2$ block 3 in P. falciparum isolates} from STP

Twenty-one haplotypes were identified in $118 \mathrm{msp} 2$ sequences, of which 11 belonged to the 3D7/IC family (IH1-IH11, GenBank accession numbers MW001393MW001403), and 10 belonged to the FC27 family (FH1-FH10, GenBank accession numbers MW001404MW001413). Nearly all the samples $(98.3 \%, 116 / 118)$ were infected by a single clone of $m s p 2$, with only $1.7 \%(2 / 118)$ presenting multi-clones of $m s p 2$ (mean $\mathrm{MOI}=1.02$ ). The $3 \mathrm{D} 7 / \mathrm{IC}$ and $\mathrm{FC} 27$ alleles were detected in $27.1 \%(32 / 118)$ and $72.9 \%(86 / 118)$ of the total isolates, respectively.

Two tandem repeat regions (R1 and R2) were flanked by three family-specific regions (E1-E3, Additional file 1 : Fig. S4) in $m s p 2$ block 3 . The R1 region in 3D7/IC haplotypes consisted of GSA-rich repeats in differed lengths, resulting in diverse polymorphisms. The R2 region of 3D7/IC was composed of 5-14 poly-threonine ( $\mathrm{T}$ ) residues, and only haplotypes $\mathrm{IH} 2$ and $\mathrm{IH} 9$ presented additional copies of the TPA motif before the poly-threonine segments. Genetic diversity of the 3D7/IC alleles was the

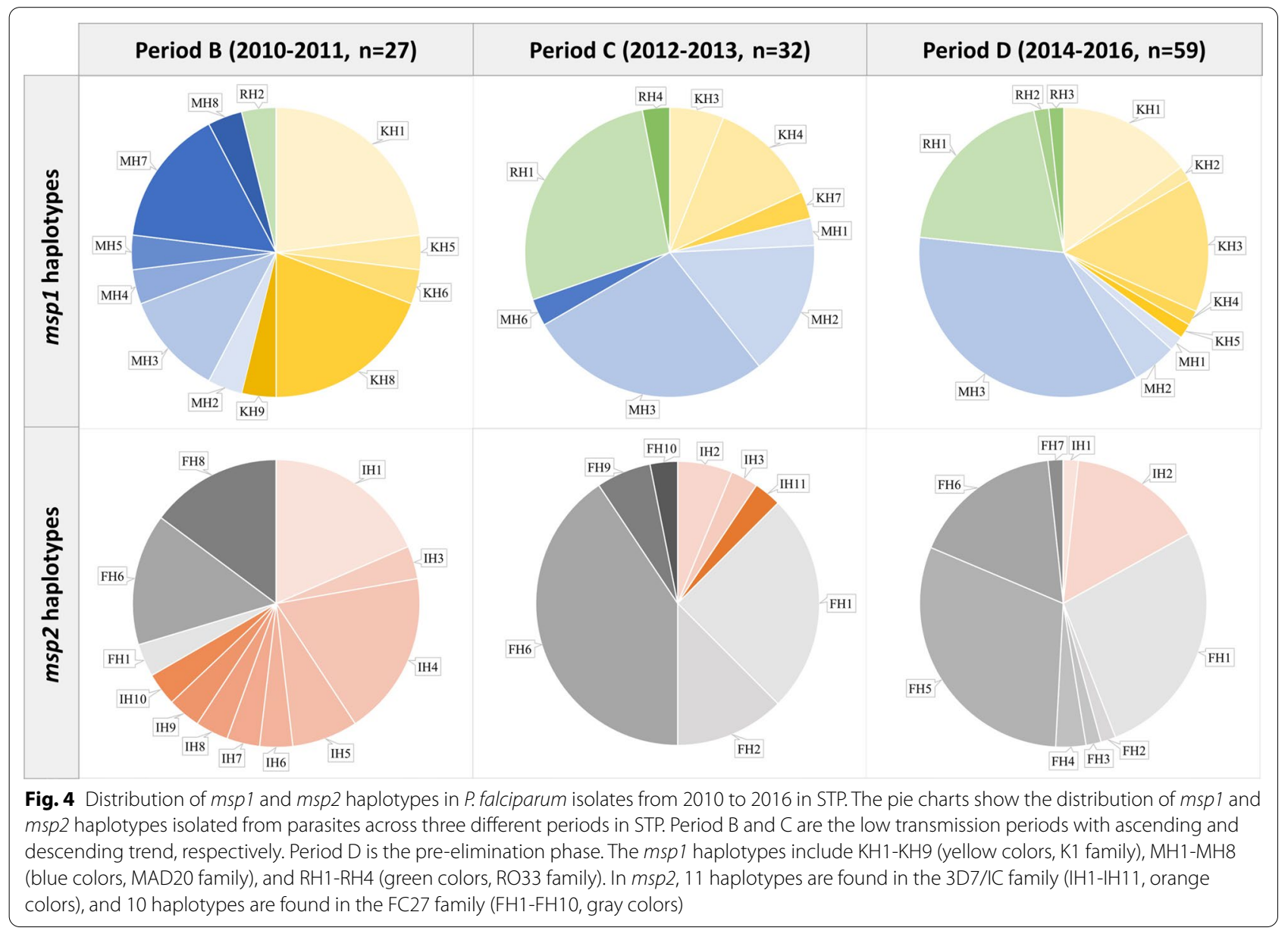


highest in 2010-2011 (9 haplotypes being detected) and then decreased to only 1-3 haplotypes with low prevalence (9-17\%) afterward (Fig. 4).

The FC27 haplotypes could be divided into two subgroups. One group included FH1, 2, and 3, containing three copies of the family-specific repeats (32 amino acids) in the R1 region, without showing tandem repeats in the $\mathrm{R} 2$ region. In contrast, the other group comprised FH4 to FH10, showing tandem repeats of 12 amino acids (aa) in the R2 region, without presenting any repeats in the R1 region (Additional file 1: Fig. S4). Among the detected FC27 types, haplotypes FH1, FH5, and FH6 were the dominant types with frequencies of $29.1 \%$ (25/86, detected in all periods), $20.9 \%$ (18/86, detected only in 2014-2016), and $31.4 \%$ (27/86, detected in all periods), respectively (Fig. 4).

Similar to $m s p 1$, the allele distribution of $m s p 2$ varied across different periods (Fig. 4). The 3D7/IC allelic family was predominant with $66.7 \%(18 / 27)$ of the prevalence before 2012; however, the prevalence declined by $50 \%$ and became minor alleles after 2012. Instead, the FC27 alleles became the predominant types, accounting for $85 \%-88 \%$ of the prevalence during and after the peak incidence.

Prevalence of anti-malarial drug resistance mutations in $P$. falciparum isolates from STP

Anti-malarial drug resistance markers were genotyped in 60 pre-treatment samples and 51 post-treatment samples collected from 2014 to 2016 . The dominant alleles were $p f m d r 1$ 86Y $(82.9 \%, 92 / 111), p f m d r 1$ 184F $(62.2 \%$, 69/111), pfmdr1 D1246 (96.4\%, 107/111), and pfcrt $76 \mathrm{~T}$ $(92.8 \%, 103 / 111)$ (Table 1). Thus, the dominant allelic types of pfmdr1 86, 184, 1246-pfcrt 76 were YFD-T (51.4\%, 57/111), followed by YYD-T $(27.0 \%, 30 / 111)$. No mutations were found in the $p f K 13$ sequences.

The post-treatment samples were from 41 patients showing inadequate treatment outcomes, of which $22 \%$ $(9 / 41)$ showed insufficient clearance of parasites on day 3, 22\% (9/41) showed early treatment failure, 31.7\% showed late parasitological failure (13/41), and $24.4 \%$ $(10 / 41)$ carried gametocytes during follow-up. Thirtyone $(75.6 \%, 31 / 41)$ of these patients were hospitalized and treated with quinine, while $10(24.4 \%, 10 / 41)$ were uncomplicated cases and treated with ASAQ on day-0. Matched-pair comparisons of pfmdr1 and pfcrt polymorphisms showed no significant differences found between the matched pre and post-treatment samples. The results showed that $83 \%(34 / 41)$ of the recurrent infections shared identical alleles of $m s p 1, m s p 2$, pfmdr1, and $p f c r t$ between pre and post-treatment samples, suggesting that the positive parasitaemia during follow-up was due to recrudescence. However, seven patients (17\%,
Table 1 Antimalarial drug-resistance mutations in the pretreatment and post-treatment samples

\begin{tabular}{|c|c|c|c|}
\hline \multirow{2}{*}{$\begin{array}{l}\text { Antimalarial } \\
\text { drug-resistance } \\
\text { markers }\end{array}$} & \multirow{2}{*}{$\begin{array}{l}\text { Pre-treatment } \\
(\mathrm{n}=60) \\
\text { No. }(\%)\end{array}$} & \multirow{2}{*}{$\begin{array}{l}\text { Post-treatment } \\
(\mathrm{n}=51) \\
\text { No. }(\%)\end{array}$} & \multirow{2}{*}{$\begin{array}{l}\begin{array}{l}\text { Total } \\
(n=111)\end{array} \\
\text { No. }(\%)\end{array}$} \\
\hline & & & \\
\hline \multicolumn{4}{|l|}{ pfmdr1 86} \\
\hline $\mathrm{N}$ & $8(13.3)$ & 10 (19.6) & $18(16.2)$ \\
\hline Y & 52 (86.7) & 14 (78.4) & $92(82.9)$ \\
\hline$N / Y$ & $0(0.0)$ & $1(2.0)$ & $1(0.9)$ \\
\hline \multicolumn{4}{|l|}{ pfmdr1 184} \\
\hline$F$ & 41 (68.3) & $28(54.9)$ & $69(62.2)$ \\
\hline Y & 19 (31.7) & $23(45.1)$ & $42(37.8)$ \\
\hline \multicolumn{4}{|l|}{ pfmdr1 1246} \\
\hline $\mathrm{D}$ & 58 (96.7) & 49 (96.1) & 107 (96.4) \\
\hline Y & $2(3.3)$ & $2(3.9)$ & $4(3.6)$ \\
\hline \multicolumn{4}{|l|}{ pfcrt 76} \\
\hline K & $1(1.7)$ & $5(9.8)$ & $6(5.4)$ \\
\hline $\mathrm{T}$ & 59 (98.3) & 44 (86.3) & 103 (92.8) \\
\hline $\mathrm{K} / \mathrm{T}$ & $0(0.0)$ & $2(3.9)$ & $2(1.8)$ \\
\hline \multicolumn{4}{|l|}{$\begin{array}{l}\text { pfmdr1 } \\
86+184+1246- \\
\text { pfcrt } 76\end{array}$} \\
\hline YFD-T & $33(55.0)$ & $24(47.1)$ & $57(51.4)$ \\
\hline YYD-T & 16 (26.7) & $14(27.5)$ & $30(27.0)$ \\
\hline NFD-T & $6(10.0)$ & $3(5.9)$ & $9(8.1)$ \\
\hline YFD-K & $2(3.3)$ & $1(2.0)$ & $3(2.7)$ \\
\hline NYD-K & $0(0.0)$ & $3(5.9)$ & $3(2.7)$ \\
\hline YYY-T & $1(1.7)$ & $1(2.0)$ & $2(1.8)$ \\
\hline NYD-K/T & $0(0.0)$ & $2(3.9)$ & $2(1.8)$ \\
\hline NYD-T & $1(1.7)$ & $1(2.0)$ & $2(1.8)$ \\
\hline NYY-T & $1(1.7)$ & $1(2.0)$ & $2(1.8)$ \\
\hline N/YYD-K & $0(0.0)$ & $1(2.0)$ & $1(0.9)$ \\
\hline
\end{tabular}

7/41) showed different $p f m d r 1$ or $p f c r t$ patterns between day- $\mathrm{R}$ and day-0 (Additional file 1: Table S1). Among these seven patients, five showed substitutions one week after treatment, while two showed early substitutions on day 3. The substitutions mainly changed from $p f m d r 1$ $86 \mathrm{Y}$ to N86, $184 \mathrm{~F}$ to $\mathrm{Y} 184, p f c r t 76 \mathrm{~T}$ to $\mathrm{K} 76$ after quinine treatment (6 patients), and ASAQ treatment (1 patient) at baseline. One patient treated with AL during followup showed substitutions from pfmdr1 86Y to N86 and pfcrt $76 \mathrm{~T}$ to $\mathrm{K} 76$ (mutation types against LF) on days 7 , 9 , and 14. Moreover, nPCR results in these seven patients showed that four were confirmed to have multi-clonal and new infections in the post-treatment samples.

Significant temporal change of $p f m d r 1$ Y184F was found in the 60 pre-treatment samples from 2014 to 2016 $\left(\mathrm{x}^{2}=8.25, \mathrm{df}=2, \mathrm{p}=0.02\right)$. The $p f m d r 1184 \mathrm{~F}$ type showed a significant increase of 39\% from 2014 to 2016 (Additional file 1: Fig. S5). The pfmdr1 86Y (75-95\%) and pfcrt 
$76 \mathrm{~T}$ (95-100\%), associated with the reduced sensitivity of $\mathrm{AQ}$, were constantly prevalent in the parasite population. The pfcrt $76 \mathrm{~T}$ mutation was nearly fixed in the local parasite population. The pfcrt 72-76 mutant type was identified as the CVIET haplotype from sequencing results.

\section{Characteristics of parasite density levels, treatment outcomes, and factors associated with parasitological recurrence}

A total of 7482 cases were analysed in the regression models (Table 2), and results showed that parasite density levels significantly decreased following the increase of age (coefficient $=-0.012, \mathrm{p}<0.001$ ). Parasite density in the infective hosts was significantly higher (coefficient $=0.4, \mathrm{p}<0.001$ ) in the low-transmission period (average $\log _{10}$ parasite density $=3.4$ ) than in the preelimination phase (average $\log _{10}$ parasite density $=2.9$ ), approximately 3.2-fold difference in the average counts of parasites in blood.

The adequate clinical and parasitological responses (ACPR) rate was $86.7 \%(6490 / 7482)$ among total cases (Fig. 5). ACPR rate in the ACT treatment group (88.297.6\%) was slightly higher than that in the quinine treatment group (73.6-94.0\%). The proportion of cases with inadequate treatment outcomes in the quinine group $(17.3 \%, 847 / 4906)$ was higher than that in the ACT group $(5.6 \%, 145 / 2576)$. In particular, patients treated with quinine were mainly hospitalized patients with higher parasitaemia levels at enrollment, and their follow-up assessments showed higher rates of insufficient clearance on day $3(0.7-14.2 \%$ in quinine group; $0.3-4.2 \%$ in ACT group), and late parasitological failure after day 7 (3.6-7.8\% in quinine group; $0.8-4.7 \%$ in ACT group). The proportion of cases treated by quinine (61.5-81.5\%) was higher than that treated by ACT $(18.5-38.5 \%)$ in

Table 2 Factors correlated with $\log _{10}$ parasite density (no. of observations $=7482$ )

\begin{tabular}{lccrr}
\hline Variables & Coefficient & SE & z value & p-value \\
\hline Age & -0.012 & 0.001 & -17.801 & $<0.001$ \\
Male & 0.011 & 0.022 & 0.516 & 0.606 \\
Endemic season & 0.033 & 0.022 & 1.474 & 0.141 \\
Period B vs. D & 0.393 & 0.031 & 12.490 & $<0.001$ \\
Period C vs. D & 0.404 & 0.028 & 14.319 & $<0.001$ \\
Urban & -0.139 & 0.070 & -1.984 & 0.050
\end{tabular}

Factors correlated with the levels of parasite density $\left(\log _{10}\right.$ transformed) are characterized using linear regression model. The definition of each variable is described in the method section. Parasite density in the low transmission periods (Period B and C, 2010-2013) are compared with that in the preelimination phase (Period D, 2014-2016) using dummy variables. Significant $p$-values $(p<0.05)$ are shown in italic the low-transmission period. Following the decrease of infective parasite density in the pre-elimination settings, cases treated by ACT were greater or nearly equal to the quinine-treated numbers, and the overall ACPR rate was higher in the pre-elimination phase $(94 \%)$ than in the low-transmission period (84.6\%).

Logistic regression models were constructed to characterize risk factors for early and late parasitological treatment failures during follow-up (Table 3). Results showed that age was a significant protective factor against parasitological treatment failures $(\mathrm{OR}=0.97$ and $0.98, \mathrm{p}<0.001$ for early and late parasitological failure, respectively). Thus, younger children had higher odds of recurrence than the elderly. In the low-transmission period, the odds of early and late parasitological failures were significantly higher than those in the pre-elimination period $(\mathrm{OR}=1.63-5.82, \mathrm{p}<0.01)$. Both parasite density $\left(\log _{10}\right.$ transformed, $\mathrm{OR}=1.44, \mathrm{p}<0.001$ ) and quinine treatment $(\mathrm{OR}=1.96, \mathrm{p}<0.001)$ had significant association with early parasitological failure. However, only quinine treatment $(\mathrm{OR}=1.91, \mathrm{p}<0.001)$ had significant association with late parasitological failure, and parasite density had no significant association with late parasitological failure after adjusting treatment types $(p=0.27$, Additional file 1: Fig. S6).

\section{Discussion}

This study tracked the dynamic changes in genetic diversity, anti-malarial drug resistance of parasites, and treatment follow-up of malaria cases in STP. The prevalent parasite strains changed during the transition time from the low-transmission to the pre-elimination settings. Moreover, patients with younger age, higher parasite density at enrollment, and receiving quinine treatment were more likely to experience recurrence during followup, which was majorly due to recrudescent infections based on the genotyping results.

A previous study analysed $180 \mathrm{P}$. falciparum isolates from STP in 2000 and showed that the frequency of $m s p 1 \mathrm{~K} 1, \mathrm{MAD} 20$, and RO33 types was $50 \%, 44 \%$, and $6 \%$, respectively [12]. This was similar to the frequency detected in the samples from 2010 to 2011 (K1 $=54 \%$, MAD20 $=42 \%, \mathrm{RO} 33=4 \%$ ) in this study. After the peak incidence in 2012, the frequencies of the MAD20 and RO33 allelic types increased and replaced K1 types as the prevalent alleles. Similar results were also found in $m s p 2$. The proportion of $m s p 23 \mathrm{D} 7 / \mathrm{IC}$ and FC27 alleles detected from 2010 to 2011 was similar to that in 2000 [12], of which 3D7/IC was the prevalent allelic type (60$65 \%)$, and FC27 was the minor type (35-40\%). However, after 2012, FC27 replaced 3D7/IC as the dominant $m s p 2$ alleles. The changing of genetic makeups could be associated with malaria transmission intensity and was shown 


\section{$\square \mathrm{ACPR} \square \mathrm{ISC} \square \mathrm{ETF} \square \mathrm{LPF} \square \mathrm{GC}$}
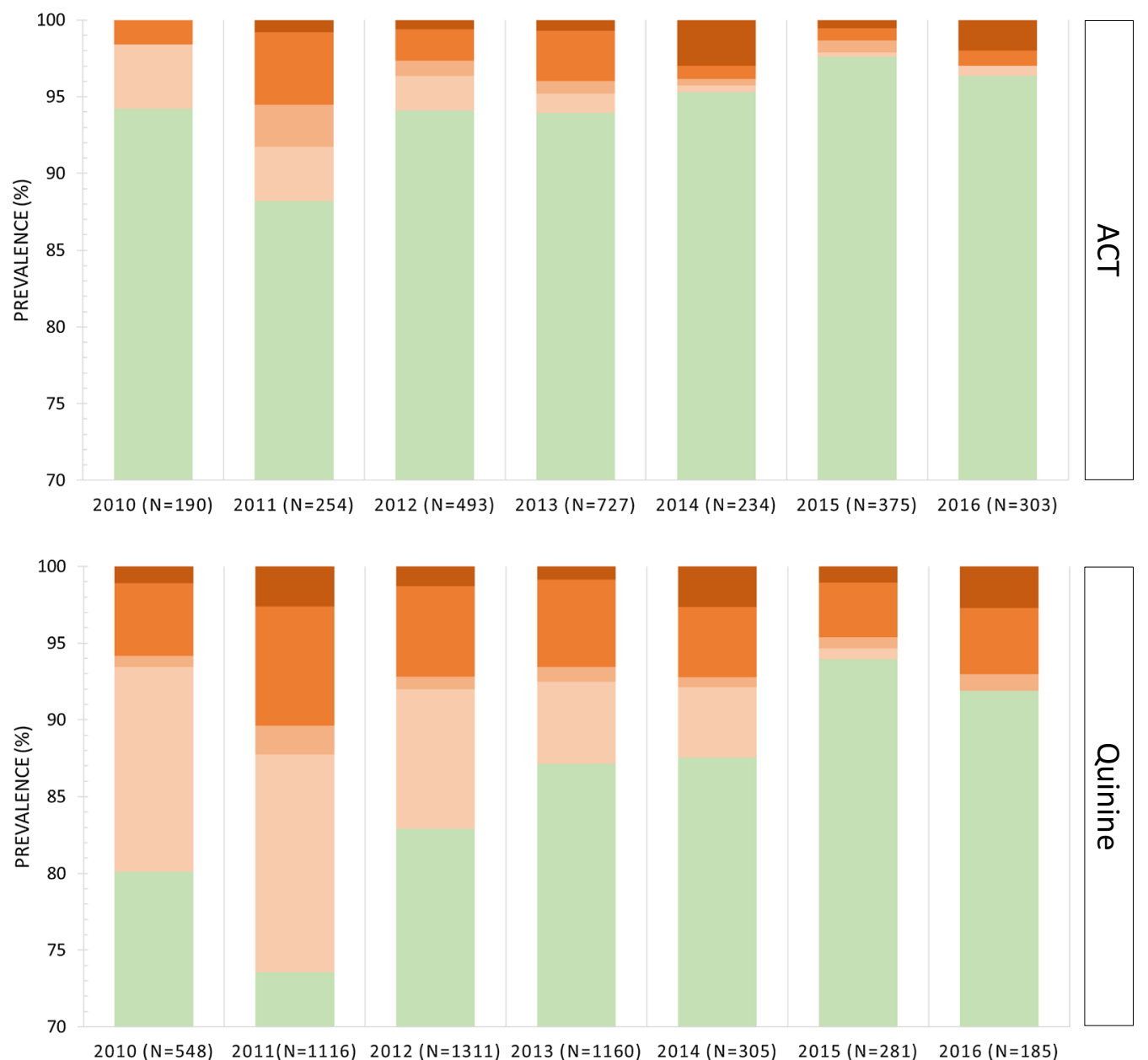

Fig. 5 Treatment outcomes of ACT and quinine from 2010 to 2016 in STP

in studies from other island countries [32,33]. For example, a generally high parasite genetic variation in $m s p 1$ and $m s p 2$ was found after deploying multiple malaria control measures since 2004 on Bioko Island, the neighboring island of STP [32]. A progressive decrease in parasite genetic diversity was observed due to the declined malaria transmission intensity after the introduction of ACT on the Grande Comore Island, located off the southeast coast of Africa [33]. Generally, STP was under low transmission intensity, and the mean MOI was low across the study period. Still, changes of $m s p 1$ and $m s p 2$ compositions in parasites were detected and coincident with the transmission trend. Although with limited sample numbers, the reasons for this changing deserved further discussion and investigation.

The haplotypes that showed expansion after 2012 in STP were $m s p 1 \mathrm{MH} 3$ and RH1, and $m s p 2$ FH5 and FH6. The $m s p 1$ MH3 and msp2 FH6 were found before 2012 and increased in frequencies afterward. The msp1 RH1 and $m s p 2$ FH 5 were not detected in the samples collected before 2012. Based on these findings, this study supposed the changes of the prevalent strains might be due to the population expansion of a few haplotypes that originally existed locally, or some new strains that may have evolved or emerged through the recombination or importation events [34-36]. The expansion of a few parasite clones could be attributed to several factors, including selective antibodies, anti-malarial drug pressures, importation, or a founder effect at the beginning of the epidemics [34, 37, 38]. Changes in the prevalent types before, during, and after the outbreak were also identified in Djibouti, Northern East Africa, and were suggested to be associated with the expansion of a few strains that were already prevalent during the epidemics in 1999 [37]. Another study in Myanmar showed that the population structure of $m s p 1$ and $m s p 2$ had diversified drastically in 2013-2015, 
Table 3 Logistic regression analyses of factors related to early and late parasitological failures (no. of observations $=7482$ )

\begin{tabular}{|c|c|c|c|c|c|}
\hline Variable & Coefficient & SE & $z$ value & $p$-value & OR $(95 \% \mathrm{Cl})$ \\
\hline \multicolumn{6}{|l|}{$\begin{array}{l}\text { Early parasitological failure } \\
\text { (day } 3 \text { positive) }\end{array}$} \\
\hline Age & -0.028 & 0.004 & -6.752 & $<0.001$ & $0.97(0.96-0.98)$ \\
\hline Male & -0.048 & 0.093 & -0.513 & 0.608 & $0.95(0.80-1.14)$ \\
\hline Urban & 0.015 & 0.254 & 0.059 & 0.953 & $1.02(0.62-1.67)$ \\
\hline Period B vs. D & 1.761 & 0.199 & 8.860 & $<0.001$ & $5.82(3.94-8.59)$ \\
\hline Period C vs. D & 1.003 & 0.199 & 5.046 & $<0.001$ & $2.73(1.85-4.03)$ \\
\hline Endemic season & 0.026 & 0.093 & 0.278 & 0.781 & $1.03(0.86-1.23)$ \\
\hline $\log _{10}$ parasite density at day $0^{*}$ & 0.368 & 0.058 & 6.379 & $<0.001$ & $1.44(1.29-1.62)$ \\
\hline Quinine* & 0.672 & 0.150 & 4.490 & $<0.001$ & $1.96(1.46-2.63)$ \\
\hline \multicolumn{6}{|l|}{$\begin{array}{l}\text { Late parasitological failure } \\
\text { (days } 7-28 \text { positive) }\end{array}$} \\
\hline Age & -0.022 & 0.005 & -4.775 & $<0.001$ & $0.98(0.97-0.99)$ \\
\hline Male & -0.173 & 0.112 & -1.542 & 0.123 & $0.84(0.67-1.05)$ \\
\hline Urban & -0.239 & 0.296 & -0.807 & 0.419 & $0.79(0.94-1.22)$ \\
\hline Period B vs. D & 0.647 & 0.189 & 3.419 & $<0.001$ & $1.91(1.32-2.77)$ \\
\hline Period C vs. D & 0.487 & 0.181 & 2.691 & 0.007 & $1.63(1.14-2.32)$ \\
\hline Endemic season & -0.089 & 0.113 & -0.788 & 0.430 & $0.91(0.73-1.14)$ \\
\hline $\log _{10}$ parasite density at day $0^{*}$ & 0.069 & 0.064 & 1.071 & 0.284 & $1.07(0.94-1.22)$ \\
\hline Quinine* $^{*}$ & 0.648 & 0.162 & 3.997 & $<0.001$ & $1.91(1.39-2.63)$ \\
\hline
\end{tabular}

The definition of each variable is described in the method section. Period B and $C$ are the low transmission periods with ascending and descending trend, respectively. Period $\mathrm{D}$ is the pre-elimination phase. The asterisk denotes that the mediation analysis was performed to examine the relationship between "parasite density $\rightarrow$ treatment $\rightarrow$ early/late parasitological failures" in Additional file 1: Fig. S6. Significant $p$-values $(p<0.05)$ are shown in italic

compared to the previous years, 2004-2006, and could be due to a higher level of intragenic recombination estimated in the recent population [36]. For islands like STP, human mobility and malaria importation are of great challenges, especially importing from mainland Africa where malaria transmission is more intense [39-41]. Examples from Bioko Island showed that much of the $P$. falciparum parasites currently observed on the island could probably be attributed to imported cases from Equatorial Guinea [40, 41]. Future studies could verify these plausible factors by utilizing more genomic, epidemiological, and mobility data to reveal the rebounded causes and threats in STP.

Anti-malarial drug resistance is another critical challenge to malaria control and elimination [42]. According to the policy decision recommended by the WHO [43], ACT should be changed if the proportion of treated patients remaining parasitaemic on day 3 exceeded $10 \%$. In STP, the proportion of patients showing positive parasitaemia on day 3 after ACT treatment was $2.5 \%$ $(63 / 2,576)$, showing that the current treatment policy was acceptable. However, by monitoring target-site mutations, this study found an increase in the pfmdr1 $86 \mathrm{Y}$ mutation compared to that in a previous study conducted in 2004 when ACT was introduced in STP [44]. The prevalence of the pfmdr1 $86 \mathrm{Y}$ mutation in parasite isolates increased from $21 \%$ in 2004 to $87 \%$ in $2014-2016$. This mutation is associated with the reduced sensitivity to AQ and chloroquine (CQ) in P. falciparum [45]. With the increased $p f m d r 186 \mathrm{Y}$ mutation and nearly fixed mutation of pfcrt $76 \mathrm{~T}$, the local parasites may show increased tolerance to $\mathrm{AQ}$, raising concerns regarding the use of AQ as the first-line ACT partner drug in STP. Other polymorphisms showed the same pattern of predominance (pfmdr1 184F and pfmdr1 D1246) as shown in the parasites isolated in 2004 [44]. Overall, the prevalent haplotype of $p f m d r 1$ and pfcrt was YFD (51.4\%) and CVIET $(92.8 \%)$, which was similar to the findings in the neighbouring Bioko island, where the pfmdr1 YFD (45-59\%) and pfcrt CVIET (92\%) were also the prevalent types from 2011 to 2014 [46, 47].

The drug-resistance genotyping results found that most parasites detected after treatment were recrudescent infections, showing identical genotypes as the initial infections. However, a few recurrent infections (seven patients) showed substitutions of drug resistance types after treatment. The observed substitutions in these seven patients could be owing to two reasons. First, multi-clonal and new infections were detected in four post-treatment samples, showing that they were infected by additional or new parasite strains that carry the alternative alleles. Second, the substitutions of AL resistant 
types (pfmdr1 $86 \mathrm{Y} \rightarrow \mathrm{N} 86$, and pfcrt $76 \mathrm{~T} \rightarrow \mathrm{K} 76$ ) were detected in patients treated by the second-line drug, $\mathrm{AL}$, during follow-up. This suggested possible rapid selection against AL treatment. However, AL was not popularly used in STP compared to ASAQ. Therefore, the drugresistance selection of AL will require further investigation with larger sample size.

This study found that young children had a higher risk of showing high parasitaemia and treatment failures, probably due to the lack of acquired immuno-protection and lower treatment compliance compared to adults [48]. Notably, patients treated with quinine were more likely to show insufficient clearance of parasites during followup than those treated with ACT. Several possible reasons were suggested as follows. First, patients treated with quinine mostly had higher parasitaemia levels, prolonging the clearance time. The mean parasite clearance time of quinine treatment was approximately $4-5$ days [ 49 , 50], which was slower than ASAQ treatment (2-3 days) in general [51], and the difference may be more significant in cases with higher parasitaemia. Second, poor compliance and tolerability with the quinine regimen may occur, especially in children. The recommended quinine regimen in sub-Saharan Africa is $10 \mathrm{mg} / \mathrm{kg}$ administered three times daily for 7 days $[43,49]$. This prolonged treatment course may reduce patients' compliance if they have to take medicines after being discharged from the hospital. Studies in Africa have found unacceptably high treatment failure rates for patients who did not complete the 7-day quinine regimen [52, 53]. One study in Uganda investigated children administered a 7-day course of oral quinine, and found 69\% (18/26) showed recrudescence during follow-up. The primary causes were poor adherence due to the caregivers forgetting to administer the drugs, the drugs being vomited up, or the children feeling better [54]. This was similar to the observations in STP. The study results also proved that most of the recurrent infections in quinine group were due to the incomplete clearance of the initially infected parasites, with only a few due to new infections. The final reason was the possible development of resistance against quinine in the parasite population. The mechanism of quinine resistance has not been well elucidated [53]. Conflicting results from the lack of resistance to varying degrees of resistance against quinine have been reported in Africa $[55,56]$. Notably, one in vitro study from Western Kenya showed polymorphisms in pfmdr1 86Y, 184F, and pfcrt $76 \mathrm{~T}$ were significantly associated with reduced quinine susceptibility in P. falciparum [57]. This suggests that the parasite strains in STP may have developed reduced sensitivity in quinine owing to the high prevalence of $p f m d r 1$ $86 \mathrm{Y}, 184 \mathrm{~F}$, and pfcrt $76 \mathrm{~T}$ detected in this study. However, the contribution of these genetic polymorphisms differed among strains; thus, the association with in vitro quinine susceptibility should be further assessed in the STP isolates [57].

Quinine has been used since chloroquine was abandoned in STP due to high resistance in the 1990s [49]. According to local regulations, it has been used for severe malaria treatment, at least until 2018 [4, 7, 15, 16, 58]. One possible reason why quinine has long been used may be that the medicinal plant for quinine (Cinchona tree) is abundant on Sao Tome and Principe Islands [59], and the communities are more adapted to quinine as one of the most-used anti-malarial drugs. However, following the WHO Guidelines for Treatment of Malaria [43] and the current findings, it was suggested to replace IV quinine with IV artesunate. According to the latest WHO malaria report 2020 [1], the local government has updated their anti-malarial drug policies in 2019, using IV artesunate to treat severe malaria now. Although no mutations were found in the artemisinin resistance marker in this study, the $p f k 13$ mutations have been reported in a few African parasites recently, for example, the emergence of $p f k 13$ mediated artemisinin resistance in Rwanda [60] and Uganda [61], which should be carefully monitored in all the African isolates in the future.

Overall, the increased outdoor mosquito density and pyrethroid resistance [4], the changes of parasites' antigenic alleles and drug resistance mutations, and a higher treatment failure in young children treated by quinine could be significant challenges for malaria elimination in STP. Moreover, surveillance data showed that malaria hotspots in STP are distributed nearby the Central Hospital (HAM), military camps, schools, markets, and airports located in the capital district, Água Grande. These are places that aggregate many people and may intensify malaria transmission. Although the higher case numbers observed in these hotspots may be due to the accessibility to medical services, poor environmental management in these densely populated locations pose a great threat to the rebound of malaria. Concerning malaria elimination, these specified risk factors and hotspots should be addressed in the policy decision-making for the national malaria control programmes in STP.

\section{Conclusion}

Although malaria treatment efficacy remained acceptable in STP, this study found that the circulating parasites underwent temporal changes of prevalent strains and increased frequency of drug resistance mutations. Case surveillance data showed that patients with younger age, higher parasitaemia level at enrollment, and receiving quinine treatment were more likely to experience recurrence during follow-up. It 
is recommended that the latest therapeutic efficacy should be monitored, at least in children and in the hotspots, to avoid the rebound in transmission and the spread of drug-resistant parasites.

\section{Supplementary Information}

The online version contains supplementary material available at https://doi. org/10.1186/s12936-021-04007-3.

Additional file 1: Fig. S1. Monthly malaria cases in HAM from 2010 to 2016. Fig. S2. Sequence alignment of MSP1 haplotypes. Fig. S3. Phylogenetic tree of the mspl sequences from STP and other countries. Fig. S4. Sequence alignment of MSP2 haplotypes. Fig. S5. Temporal changes of pfmdr1 and pfcrt polymorphisms in 60 pre-treatment samples from 2014 to 2016. Fig. S6. Relationship between initial parasite density, treatment types, and parasitological treatment failures. Table S1. Substitutions of pfmdr 1 and pfcrt genotypes after treatment in seven recurrent infections.

\section{Acknowledgements}

The authors would like to thank the Taiwan Anti-Malaria Advisory Mission for their enthusiastic participation and professional assistance, especially Dr. Jih-Ching Lien (project leader) and Ms. Lien-Fen Tseng (coordinator). We are grateful to Dr. Maria de Jesus Trovoada dos Santos, Dr. Arlindo Carvalho, and Mr. João Viegas d'Abreu to communicate with the local participants and laboratory workers.

\section{Authors' contributions}

YAC and KHT: initiated study hypothesis. YAC undertook the analysis and drafted the manuscript. KHT, LFT, CFC, and AC (Taiwan Anti-Malaria Advisory Mission members and local health workers): proofread the data and the manuscript. WLS: supervised statistical analysis. KHT: supervision and correspondence. All authors have read and approved the final manuscript.

\section{Funding}

This study was financially supported by the Ministry of Foreign Affairs, Republic of China (Taiwan), and grants from the Ministry of Science and Technology Council (103-2314-B-002-036-MY2)

\section{Availability of data and materials}

All data generated or analyzed in this study are included in this published article and its additional files.

\section{Declarations}

\section{Ethics approval and consent to participate}

The content and methods used in this study have been reviewed and approved by the Centro Nacional de Endemias of the Ministry of Health in STP $\left(\mathrm{OF}^{\circ} \mathrm{N}^{\circ} 20 / \mathrm{P}^{\circ} \mathrm{CNE} / 2016\right)$ and the Research Ethics Committee of National Taiwan University Hospital (NTUH-REC No. 201110023RD).

\section{Consent for publication}

Not applicable.

\section{Competing interests}

The authors declare that they have no competing interests.

\section{Author details}

${ }^{1}$ Institute of Environmental and Occupational Health Sciences, College of Public Health, National Taiwan University, Taipei, Taiwan. ${ }^{2}$ Institute of Epidemiology and Preventive Medicine, College of Public Health, National Taiwan University, Taipei, Taiwan. ${ }^{3}$ Taiwan Anti-Malaria Advisory Mission, São Tomé, São Tomé and Príncipe. ${ }^{4}$ Infectious Diseases Research and Education Center, Ministry of Health and Welfare and National Taiwan University, Taipei, Taiwan. ${ }^{5}$ Centro Nacional de Endemias, Ministério da Saúde de São Tomé e Príncipe, São
Tomé, São Tomé and Príncipe. ${ }^{6}$ Department of Public Health, College of Public Health, National Taiwan University, Taipei, Taiwan.

Received: 30 August 2021 Accepted: 3 December 2021

Published online: 14 December 2021

\section{References}

1. WHO. World malaria report 2020. Geneva, World Health Organization, 2020.

2. Ashton RA, Prosnitz D, Andrada A, Herrera S, Yé Y. Evaluating malaria programmes in moderate- and low-transmission settings: practical ways to generate robust evidence. Malar J. 2020;19:75.

3. WHO. A framework for malaria elimination. Geneva, World Health Organization, 2017

4. Chen YA, Lien JC, Tseng LF, Cheng CF, Lin WY, Wang HY, et al. Effects of indoor residual spraying and outdoor larval control on Anopheles coluzzii from São Tomé and Príncipe, two islands with pre-eliminated malaria. Malar J. 2019;18:405.

5. Tseng LF, Chang WC, Ferreira MC, Wu CH, Rampão HS, Lien JC. Rapid control of malaria by means of indoor residual spraying of alphacypermethrin in the Democratic Republic of São Tomé and Príncipe. Am J Trop Med Hyg. 2008;78:248-50.

6. Pinto J, Sousa CA, Gil V, Ferreira C, Goncalves L, Lopes D, et al. Malaria in Sao Tome and Principe: parasite prevalences and vector densities. Acta Trop. 2000;76:185-93.

7. Lee PW, Liu CT, do Rosario VE, de Sousa B, Rampao HS, Shaio MF. Potential threat of malaria epidemics in a low transmission area, as exemplified by Sao Tome and Principe. Malar J. 2010;9:264.

8. Salgueiro P, Vicente JL, Figueiredo RC, Pinto J. Genetic diversity and population structure of Plasmodium falciparum over space and time in an African archipelago. Infect Genet Evol. 2016;43:252-60.

9. Beeson JG, Drew DR, Boyle MJ, Feng G, Fowkes FJ, Richards JS. Merozoite surface proteins in red blood cell invasion, immunity and vaccines against malaria. FEMS Microbiol Rev. 2016;40:343-72.

10. Conway DJ, Cavanagh DR, Tanabe K, Roper C, Mikes ZS, Sakihama N, et al. A principal target of human immunity to malaria identified by molecular population genetic and immunological analyses. Nat Med. 2000;6:689-92.

11. Snounou G, Zhu X, Siripoon N, Jarra W, Thaithong S, Brown KN, et al. Biased distribution of msp1 and msp2 allelic variants in Plasmodium falciparum populations in Thailand. Trans R Soc Trop Med Hyg. 1999:93:369-74.

12. Mwingira F, Nkwengulila G, Schoepflin S, Sumari D, Beck H-P, Snounou G, et al. Plasmodium falciparum msp1, msp2 and glurp allele frequency and diversity in sub-Saharan Africa. Malar J. 2011;10:79.

13. Miller LH, Roberts T, Shahabuddin M, McCutchan TF. Analysis of sequence diversity in the Plasmodium falciparum merozoite surface protein-1 (MSP1). Mol Biochem Parasitol. 1993;59:1-14.

14. Smythe JA, Coppel RL, Day KP, Martin RK, Oduola AM, Kemp DJ, et al. Structural diversity in the Plasmodium falciparum merozoite surface antigen 2. Proc Natl Acad Sci USA. 1991;88:1751-5.

15. Teklehaimanot HD, Teklehaimanot A, Kiszewski A, Rampao HS, Sachs JD. Malaria in Sao Tome and Principe: on the brink of elimination after three years of effective antimalarial measures. Am J Trop Med Hyg. 2009:80:133-40.

16. Lee PW, Liu CT, Rampao HS, do Rosario VE, Shaio MF. Pre-elimination of malaria on the island of Principe. Malar J. 2010;9:26.

17. Ashley EA, Dhorda M, Fairhurst RM, Amaratunga C, Lim P, Suon S, et al. Spread of artemisinin resistance in Plasmodium falciparum malaria. N Engl J Med. 2014;371:411-23.

18. Haldar K, Bhattacharjee S, Safeukui I. Drug resistance in Plasmodium. Nat Rev Microbiol. 2018;16:156.

19. Venkatesan M, Gadalla NB, Stepniewska K, Dahal P, Nsanzabana C, Moriera C, et al. Polymorphisms in Plasmodium falciparum chloroquine resistance transporter and multi-drug resistance 1 genes: parasite risk factors that affect treatment outcomes for $P$. falciparum malaria after artemether-lumefantrine and artesunate-amodiaquine. Am JTrop Med Hyg. 2014;91:833-43. 
20. Tomás G, Seco L, Seixas S, Faustino P, Lavinha J, Rocha J. The peopling of São Tomé (Gulf of Guinea): origins of slave settlers and admixture with the Portuguese. Hum Biol. 2002;74:397-411.

21. Wooden J, Kyes S, Sibley CH. PCR and strain identification in Plasmodium falciparum. Parasitol Today. 1993;9:303-5.

22. Somé AF, Bazié T, Zongo I, Yerbanga RS, Nikiéma F, Neya C, et al. Plasmodium falciparum msp1 and msp2 genetic diversity and allele frequencies in parasites isolated from symptomatic malaria patients in Bobo-Dioulasso, Burkina Faso. Parasit Vectors. 2018:11:323.

23. Mekong Molecular Surveillance Network. Molecular testing for malaria standard operating procedure (SOP). Manual size estimation of $\mathrm{msp}$ 1, msp2 and glurp PCR products on gel. Worldwide Antimalarial Resistance Network (WWARN) 2014. https://www.wwarn.org/tools-resou rces/procedures/manual-size-estimation-msp1-msp2-and-glurp-pcrproducts-gel.

24. WHO. Methods and techniques for clinical trials on antimalarial drug efficacy: genotyping to identify parasite populations. Geneva, World Health Organization, 2007.

25. Mehlotra RK, Fujioka H, Roepe PD, Janneh O, Ursos LMB, Jacobs Lorena $\checkmark$, et al. Evolution of a unique Plasmodium falciparum chloroquineresistance phenotype in association with pfcrt polymorphism in Papua New Guinea and South America. Proc Natl Acad Sci USA. 2001;98:12689-94.

26. Lu F, Culleton $R$, Zhang M, Ramaprasad A, von Seidlein $L$, Zhou $H$, et al. Emergence of indigenous artemisinin-resistant Plasmodium falciparum in Africa. N Engl J Med. 2017;376:991-3.

27. Lopes D, Rungsihirunrat K, Nogueira F, Seugorn A, Gil JP, do Rosário VE, et al. Molecular characterisation of drug-resistant Plasmodium falciparum from Thailand. Malar J. 2002;1:12

28. Veiga MI, Ferreira PE, Bjorkman A, Gil JP. Multiplex PCR-RFLP methods for pfcrt, pfmdr1 and pfdhfr mutations in Plasmodium falciparum. Mol Cell Probes. 2006;20:100-4.

29. Kang JM, Moon SU, Kim JY, Cho SH, Lin K, Sohn WM, et al. Genetic polymorphism of merozoite surface protein-1 and merozoite surface protein-2 in Plasmodium falciparum field isolates from Myanmar. Malar J. 2010;9:131.

30. WHO. Methods for surveillance of antimalarial drug efficacy. Geneva, World Health Organization, 2009.

31. WHO. Malaria terminology. Geneva, World Health Organization, 2016.

32. Chen JT, Li J, Zha GC, Huang G, Huang ZX, Xie DD, et al. Genetic diversity and allele frequencies of Plasmodium falciparum msp 1 and msp2 in parasite isolates from Bioko Island, Equatorial Guinea. Malar J. 2018;17:458.

33. Huang $B$, Tuo F, Liang $Y$, Wu W, Wu G, Huang $S$, et al. Temporal changes in genetic diversity of $m s p-1, m s p-2$, and msp-3 in Plasmodium falciparum isolates from Grande Comore Island after introduction of ACT. Malar J. 2018;17:83.

34. Daniels R, Chang HH, Séne PD, Park DC, Neafsey DE, Schaffner SF, et al. Genetic surveillance detects both clonal and epidemic transmission of malaria following enhanced intervention in Senegal. PLOS ONE. 2013;8 e60780.

35. Obaldia N 3rd, Baro NK, Calzada JE, Santamaria AM, Daniels R, Wong W, et al. Clonal outbreak of Plasmodium falciparum infection in eastern Panama. J Infect Dis. 2015;211:1087-96.

36. Lê HG, Kang JM, Jun H, Lee J, Thái TL, Myint MK, et al. Changing pattern of the genetic diversities of Plasmodium falciparum merozoite surface protein- 1 and merozoite surface protein-2 in Myanmar isolates. Malar J. 2019;18:241.

37. Rogier C, Pradines B, Bogreau H, Koeck JL, Kamil MA, Mercereau PO. Malaria epidemic and drug resistance, Djibouti. Emerg Infect Dis. 2005;11:317-21.

38. Noranate N, Prugnolle F, Jouin H, Tall A, Marrama L, Sokhna C, et al. Population diversity and antibody selective pressure to Plasmodium falciparum MSP1 block2 locus in an African malaria-endemic setting. BMC Microbiol. 2009;9:219.

39. Guerra CA, Fuseini G, Donfack OT, Smith JM, Ondo Mifumu TA, Akadiri $\mathrm{G}$, et al. Malaria outbreak in Riaba district, Bioko Island: lessons learned. Malar J. 2020;19:277.

40. Guerra CA, Kang SY, Citron DT, Hergott DEB, Perry M, Smith J, et al. Human mobility patterns and malaria importation on Bioko Island. Nat Commun. 2019;10:2332.
41. Bradley J, Monti F, Rehman AM, Schwabe C, Vargas D, Garcia G, et al. Infection importation: a key challenge to malaria elimination on Bioko Island, Equatorial Guinea. Malar J. 2015;14:46.

42. Menard D, Dondorp A. Antimalarial drug resistance: a threat to malaria elimination. Cold Spring Harb Perspect Med. 2017;7: a025619.

43. WHO. Guidelines for the Treatment of Malaria (3rd edn). Geneva, World Health Organization, 2015.

44. Ferreira ID, Lopes D, Martinelli A, Ferreira C, Do Rosário VE, Cravo P. In vitro assessment of artesunate, artemether and amodiaquine susceptibility and molecular analysis of putative resistance-associated mutations of Plasmodium falciparum from São Tomé and Príncipe. Trop Med Int Health. 2007;12:353-62.

45. Cowell AN, Winzeler EA. The genomic architecture of antimalarial drug resistance. Brief Funct Genomics. 2019;18:314-28.

46. Li J, Chen J, Xie D, Monte Nguba SM, Eyi JUM, Matesa RA, et al. High prevalence of pfmdr1 N86Y and Y184F mutations in Plasmodium falciparum isolates from Bioko Island, Equatorial Guinea. Pathog Glob Health. 2014;108:339-43.

47. Li J, Chen J, Xie D, Eyi UM, Matesa RA, Obono MMO, et al. Molecular mutation profile of Pfcrt and Pfmdr1 in Plasmodium falciparum isolates from Bioko Island, Equatorial Guinea. Infect Genet Evol. 2015;36:552-6.

48. Sondo P, Derra K, Lefevre T, Diallo Nakanabo S, Tarnagda Z, Zampa O, et al. Genetically diverse Plasmodium falciparum infections, within-host competition and symptomatic malaria in humans. Sci Rep. 2019;9:127.

49. Baptista JL, Das Neves I, D'Alessandro U, Hendrix L, Wéry M. Plasmodium falciparum chloroquine and quinine sensitivity in asymptomatic and symptomatic children in São Tomé Island. Trop Med Int Health. 1997;2:582-8.

50. Esamai F, Tenge CN, Ayuo PO, Ong'or WO, Obala A, Jakait B. A randomized open label clinical trial to compare the efficacy and safety of intravenous quinine followed by oral malarone vs intravenous quinine followed by oral quinine in the treatment of severe malaria. J Trop Pediatr. 2005;51:17-24.

51. Mårtensson A, Strömberg J, Sisowath C, Msellem MI, Gil JP, Montgomery SM, et al. Efficacy of artesunate plus amodiaquine versus that of artemether-lumefantrine for the treatment of uncomplicated childhood Plasmodium falciparum malaria in Zanzibar, Tanzania. Clin Infect Dis. 2005:41:1079-86.

52. Kofoed PE, Mapaba E, Lopes F, Pussick F, Aaby P, Rombo L. Comparison of 3, 5 and 7 days' treatment with Quinimax for falciparum malaria in Guinea-Bissau. Trans R Soc Trop Med Hyg. 1997;91:462-4.

53. Achan J, Talisuna AO, Erhart A, Yeka A, Tibenderana JK, Baliraine FN, et al. Quinine, an old antimalarial drug in a modern world: role in the treatment of malaria. Malar J. 2011;10:144.

54. Achan J, Tibenderana JK, Kyabayinze D, Wabwire Mangen F, Kamya MR, Dorsey G, et al. Effectiveness of quinine versus artemether-lumefantrine for treating uncomplicated falciparum malaria in Ugandan children: randomised trial. BMJ. 2009;339: b2763.

55. Tinto H, Rwagacondo C, Karema C, Mupfasoni D, Vandoren W, Rusanganwa E, et al. In-vitro susceptibility of Plasmodium falciparum to monodesethylamodiaquine, dihydroartemisinin and quinine in an area of high chloroquine resistance in Rwanda. Trans R Soc Trop Med Hyg. 2006:100:509-14.

56. Pradines B, Mabika Mamfoumbi M, Parzy D, Owono Medang M, Lebeau C, Mourou Mbina JR, et al. In vitro susceptibility of Gabonese wild isolates of Plasmodium falciparum to artemether, and comparison with chloroquine, quinine, halofantrine and amodiaquine. Parasitology. 1998;117:541-5.

57. Cheruiyot J, Ingasia LA, Omondi AA, Juma DW, Opot BH, Ndegwa JM, et al. Polymorphisms in Pfmdr1, Pfcrt, and Pfnhel genes are associated with reduced in vitro activities of quinine in Plasmodium falciparum isolates from western Kenya. Antimicrob Agents Chemother. 2014;58:3737-43.

58. WHO. World malaria report 2019. Geneva, World Health Organization, 2019.

59. Silva JRdA, Ramos AdS, Machado M, de Moura DF, Neto Z, CantoCavalheiro MM, et al. A review of antimalarial plants used in traditional medicine in communities in Portuguese-speaking countries: Brazil, Mozambique, Cape Verde, Guinea-Bissau, São Tomé and Príncipe and Angola. Mem Inst Oswaldo Cruz. 2011;106:142-58. 
60. Uwimana A, Legrand E, Stokes BH, Ndikumana J-LM, Warsame $\mathrm{M}, \mathrm{Umulisa} \mathrm{N}$, et al. Emergence and clonal expansion of in vitro artemisinin-resistant Plasmodium falciparum kelch13 R561H mutant parasites in Rwanda. Nat Med. 2021;27:1113-5.

61. Balikagala B, Fukuda N, Ikeda M, Katuro OT, Tachibana S-I, Yamauchi M, et al. Evidence of artemisinin-resistant malaria in Africa. N Engl J Med. 2021;385:1163-71.

\section{Publisher's Note}

Springer Nature remains neutral with regard to jurisdictional claims in published maps and institutional affiliations.

- fast, convenient online submission

- thorough peer review by experienced researchers in your field

- rapid publication on acceptance

- support for research data, including large and complex data types

- gold Open Access which fosters wider collaboration and increased citations

- maximum visibility for your research: over 100M website views per year

At BMC, research is always in progress.

Learn more biomedcentral.com/submissions 